\title{
OUTCOMES
}

\section{Peer Responses to Trans Youth Tweeting About Self-Harm and Suicidality}

\author{
Drew Simms, MSc, BSc, BA (hons) (1)
}

\begin{abstract}
Background: Transgender youth have been found to be at higher risk of experiencing common mental health problems than their cisgender peers, but there has been little research into the mechanisms of peer support among this group. Research into how young people communicate about self-harm and suicidality on social media has found patterns of behavior in which young people encourage each other's risky and self-injurious actions, but whether this holds true among minority groups such as trans youth has not been established. Method: Twitter biographies were searched to find selfidentifying trans people aged 14-18 years. The resulting accounts were searched for key words related to common mental health issues. The tweets caught by the search terms and their replies were coded into themes using a combination of inductive and deductive coding. The occurrence of themes were quantified and analyzed using SPSS 24. Results: 1,468 tweets were analyzed from 235 accounts; 133 (56.6\%) of the accounts with relevant content received no public replies to tweets mentioning mental health issues. Of the $102(43.4 \%)$ that did receive public replies, $64(62.7 \%)$ received a maximum of two replies. Three themes were found in replies to tweets, Support, Feeling the Same Way, and Advice. Most replies were expressions of support, followed by expressions of feeling the same way; advice was rare. There were no incidents of replies that were dismissive of or encouraged self-injurious behavior. Discussion: Findings differ from existing research on how youth interact with each other online with regard to mental health issues: the trans youth in this study were not found to encourage risky and self-injurious behavior in each other. This has implications for caring for trans youth in mental health settings, where social media use is normally discouraged, as its use may be a protective factor for trans youth specifically.
\end{abstract}

Keywords: transgender; youth; self-harm; suicide; peer support; social media

$\mathrm{T}$ ransgender youth experience self-harm and suicidality at a higher rate than their cisgender (non-trans) peers (Holt, Skagerberg, \& Dunsford, 2015; Rimes, Goodship, Ussher, Baker, \& West, 2017; Russell, Rasmussen, \& Hunter, 2018). Theories as to why this is the case commonly point to a combination of gender dysphoria and minority stress (Meyer \& Frost, 2013; Rood et al., 2016). Best practice for the treatment of gender dysphoria is gender-affirming health care (National Health Service, 2016); the most effective interventions for tackling minority stress are more complex, but strong social networks are known to be protective against self-harm and other risk factors (Claes et al., 2015). Little is known about the role of online social support for trans youth who are experiencing mental distress, but the use of social media by the general population of young people has long been under scrutiny for its potential influence on self-harm and suicidality.
In a review of the literature, Daine et al. (2013) found a mix of positive and negative features of young people posting about self-harm and suicidality on social media. Participants report using social media to seek out community where they can receive empathy and support, but not advice. Its value as a coping mechanism was emphasized, and the option of anonymity was helpful to participants in communicating about this sensitive subject. Negative features included the normalizing of self-harm and increasing ideation about self-harm and suicide. Some participants reported that finding "suicide partners" was relevant to their use of social media.

In a content analysis of replies to suicidal tweets, O'Dea et al. (2018) found that $23 \%$ of first replies to suicidal tweets were dismissive or encouraged suicide, and in a network analysis, Colombo, Burnap, Hodorog, and Scourfield (2016) found clusters of suicidal Twitter users who were highly connected, 


\section{Feeling that they have no outlet to talk has been identified as a risk factor for suicidality among LGBT+ youth, so the opportunity to share their thoughts and feelings online with relative anonymity may be a protective factor for trans youth.}

leading them to suggest a contagion model of information cascade in the form of suicidal retweets. Such findings occur across social media platforms: research into hashtag (\#) use on Instagram found a community of users who shared images of self-harm referring to themselves as a "secret family" (Moreno, Ton, Selkie, \& Evans, 2016). Conversely Spates, Ye, and Johnson (2018) found that in 4,524 tweets about suicide, the majority were passive expressions of wanting to die rather than expressions of active intent, and there was a proliferation of resource sharing (e.g., suicide hotlines).

Given the research findings about the protective nature of strong social networks, but also the potential risks of social media for those already predisposed to self-harm and suicidality, it is important to investigate how trans youth are using social media to discuss mental health and the nature of the reception this discussion receives among their peers.

Twitter is an ideal source of data for researching stigmatized minority groups because, in contrast to the default publicness of the platform, it is easy for users to remain anonymous if they wish by not using their legal name or other identifiable data. This anonymity means that LGBT+ youth can explore their identity and practice talking about it with others before "coming out" (Craig \& McInroy, 2014). Feeling that they have no outlet to talk has been identified as a risk factor for suicidality among LGBT+ youth (McDermott, Hughes, \& Rawlings, 2017), so the opportunity to share their thoughts and feelings online with relative anonymity may be a protective factor for trans youth.

Research that has used Twitter to investigate its use by transgender populations has for the most part relied on common hashtags (Krueger \& Young, 2015); this method has its uses, but when talking about their own mental health, it is questionable how commonly people include hashtags.
Hashtags are designed to make tweets easier to find, so their use is an implicit invitation for strangers to read them. Searching Twitter feeds for keywords reveals tweets that are public but that have not necessarily been boosted by hashtags; this is likely to result in valuable data because research shows that LGBT+ youth are acutely conscious of not wanting to appear "attention seeking" (McDermott, Hughes, \& Rawlings, 2018; Pardoe \& Trainor, 2017), a label hashtag-use can be seen as falling under.

\section{AIMS}

This study aimed to discover to what extent trans youth tweet about self-harm and suicidality, how their peers respond, and whether this differs from existing findings regarding the general population of young people on social media.

\section{METHOD}

This study used data from a larger research project conducted by the author into how trans youth disclose and discuss common mental health issues on Twitter, using Quantitative Content Analysis (QCA; Caliandro \& Gandini, 2016).

Twitter research guides (Murphy, 2017) advise using software to thematically analyze tweets due to the large data sets that searching Twitter would normally produce, but as the target population of this study is a very small minority, it was possible for a single researcher to code all the relevant tweets manually. Coding was conducted using a mix of inductive and deductive approaches outlined below, as this method collects data on the topics of interest as well as bringing in related data that was not anticipated by the researcher but adds value to the results (Fereday \& Muir-Cochrane, 2006).

\section{Ethics}

The ethical guides consulted for this research advise that while consent does not need to be sought for information that already exists in the public sphere, such data needs to be used responsibly and for the public good (Caliandro \& Gandini, 2016; Eynon, Fry, \& Schroeder, 2008). All users of Twitter must agree to the terms and conditions of use, which include confirming that they understand that the default privacy setting of accounts is public unless they chose to "protect" the account after registering. Despite this implicit consent, "Default Publicness," while commonplace, is far 
Expressing distress may be an end in itself for many trans youth, as a form of catharsis or to build a narrative that makes sense of their difficult experiences.

from neutral, and makes some groups more vulnerable than others (Cho, 2018). The topic of this research prompts extra considerations as many of the participants report their age as under 18 , the subject of interest is of a sensitive nature, and none of the participants could reasonably have foreseen their data being used for this purpose. To adjust for these factors, account names have not been included in this report and the example tweets have been edited so that they cannot be traced back to the original authors. This caution is due to the risks faced by transgender youth if they are "outed" by others, a caution that reflects the concerns expressed by LGBT+ youth themselves (Hanckel, Vivienne, Byron, Robards, \& Churchill, 2019).

\section{Inclusion Criteria}

- Accounts in which the biography identifies them as being written by someone aged 14-18 and transgender or non-binary.

- Accounts that are set to public.

\section{Exclusion Criteria}

- Accounts that are primarily for the creator's business rather than personal, for example, taking art commissions.

- Accounts that are not primarily written in English.

\section{Searching Accounts}

The application programming interface Followerwonk.com was used to search all public Twitter bios. Searches were performed using the formulation "(age) (pronoun) trans" for each age and pronoun combination: $14-18$, he/she/they, 15 searches total.

Accounts were manually filtered for inclusion by the author, removing false hits for example, "trans guy, he/him, research assistant, Texas. HRT- 12/05/17."

\section{Searching Content}

Twitter's search function was used to search for common issues among trans youth: "depression," "selfharm," "anxiety," "suicide," "eating disorders." This search was not specific to the included accounts, but a preliminary search of Twitter's entire contents to establish common words used by members of the site when tweeting about these issues. The resulting search term was "TW, depression, depressed, self-harm, SH, overdose, OD, eating disorder, ED, anorexia, bulimia, restrict, purge, anxiety, anxious, suicide, KMS, kill myself, cut, die." Twitter's advanced search engine was then used to search tweets from the accounts discovered in the bio search to find tweets that included those keywords.

Tweets were manually filtered for relevance by the author. Tweets were deemed relevant if they referred to the account holder's mental health issues, excluding general mental health awareness/activism and false hits. Tweets that were found to be relevant were copied into password-protected word documents, including any interaction the tweets received: replies, retweets, and likes.

\section{Analyzing Relevant Content}

The thematic analysis was conducted manually by the author. To perform a quantified content analysis (QCA) of these tweets, the issues of primary interest to the research question (i.e., depression, anxiety, suicidality, non-suicidal self-injury [NSSI], and eating disorders), acted as an a priori coding template. Self-reporting was recorded when reference was made to diagnoses (explicit self-report of depression, social anxiety, anorexia etc.); no attempt was made by the author to apply diagnostic criteria to the account holders.

An inductive approach was used to identify other themes as the data was read and reread to discover any other common themes that occurred alongside the issues of interest. These themes were quantified; if they occurred in more than $5 \%$ of the accounts they were deemed common enough to be included in further analysis. As well as recording how often different themes occurred and from how many accounts, it was also noted how often different themes emerged in the same context (e.g., how often depression and anxiety are tweeted about together).

\section{Analyzing Responses}

Inductive coding was also used to identify themes in the replies that the included tweets received, to 
TABLE 1. Accounts With Relevant Content by Age and Gender $\boldsymbol{n}(\%)$

\begin{tabular}{lccrrrr}
\hline Gender & \multicolumn{7}{c}{ Age } \\
\cline { 2 - 7 } & 14 & 15 & 16 & 17 & \multicolumn{1}{c}{18} & Total \\
\hline Trans male & $8(3.4)$ & $16(6.8)$ & $22(9.4)$ & $28(11.9)$ & $55(23.4)$ & $125(53.2)$ \\
Trans female & $4(1.7)$ & $7(2.9)$ & $12(5.1)$ & $16(6.8)$ & $38(16.2)$ & $76(32.3)$ \\
Non-binary & 0 & $7(2.9)$ & $8(3.4)$ & $6(2.6)$ & $17(7.2)$ & $34(14.5)$ \\
Total & $12(5.1)$ & $28(11.9)$ & $39(16.6)$ & $49(20.9)$ & $107(45.5)$ & $235(100)$ \\
\hline
\end{tabular}

establish how the online community around the account holders responded to their reporting mental health issues. These responses were categorized by theme, the theme of the tweet they were responding to, and the age and gender of the account holder the original tweet was produced from.

\section{Reliability}

Data was coded twice by the author and compared; discrepancies were examined and resolved with reference to the initial coding template, examining the wider context of the content of the tweeting account to ensure the best possible intra-coding reliability.

\section{Qualitative Analysis}

SPSS v.24 was used to perform Pearson $R$ tests of correlation and to produce descriptive statistics and frequencies.

\section{RESULTS}

Of 1,025 accounts found, 679 met the inclusion criteria: $373(54.9 \%)$ were trans males, $205(30.1 \%)$ were trans females, and $101(14.8 \%)$ were non-binary youth. Of all 679 accounts, $34.6 \%(N=235)$ contained tweets with content about mental health issues, which were collected for further analysis. See Table 1 for age and gender demographics of accounts with tweets collected for analysis.

The total number of tweets from these accounts that were used for further analysis, after being filtered for relevance, was 1,468. While 18-year-olds and trans males were overrepresented in the sample, 16-yearolds and non-binary youth tweeted the most about mental health issues relative to the sample size of their respective age and gender categories.

\section{Tweets About Self-Harm and Suicidality}

Tweets reporting suicidal thoughts were by far the most common across all genders (45.5\%-48.1\%), followed by self-harm (11.1\%-14.7\%); reports of suicide attempts were relatively rare $(2.8 \%-9.3 \%)$. All three topics of interest were most commonly tweeted by trans males. See Table 2.

Of the three topics of interest, suicidal thoughts were most likely to be tweeted about by the same user multiple times. See Table 3.

\section{Replies to Tweets Mentioning Mental Health Issues}

Of the accounts with relevant content, 133 (56.6\%) received no public replies to tweets mentioning mental health issues, although many replies were unavailable for analysis due to coming from locked accounts, and there is no way to know how many people who read the tweets reached out via other media such as direct messages. Of the $102(43.4 \%)$ accounts that did receive public replies, $64(62.7 \%)$ of these received a maximum of two replies. See Table 4 for the main themes found in replies.

\section{Analysis: Pearson Correlations of Replies}

The strongest correlation with receiving any reply was a moderate one with suicidal thoughts $(r=.473$, $p<.005)$, followed by self-harm $(r=.300, p<.005)$. Divided by theme, replies that offered general support had the same correlation trends and similar strengths as total replies, with slightly lower Pearson scores.

There were moderate to weak significant correlations between replies expressing a similar experience and all defined tweet themes, the strongest being suicidal thoughts $(r=.348, p<.005)$. While it occurred in replies to only $3.8 \%(N=9)$ of accounts, the theme of advice was moderately significantly correlated with self-harm $(r=.665, p<.005)$, followed by suicidal thoughts $(r=.474, p<.005)$. No significant negative correlations were found in the data. 
TABLE 2. Twitter Accounts With Mental Health Content by Topic of Interest $(n) \%$

\begin{tabular}{llll}
\hline & Trans Males & Trans Females & Non-Binary \\
\hline Self-harm & $(19) 14.7$ & $(11) 14.3$ & (4) 11.1 \\
Suicidal thoughts & $(62) 48.1$ & $(35) 45.5$ & (17) 47.2 \\
Suicide attempts & $(12) 9.3$ & $(3) 3.9$ & (1) 2.8 \\
\hline
\end{tabular}

TABLE 3. Number of Mentions of Each Topic per Account

\begin{tabular}{lcccc}
\hline & Minimum & Maximum & Mean & $S D$ \\
\hline Number of mentions of self-harm & 0 & 35 & .37 & 2.383 \\
Number of mentions of suicidal thoughts & 0 & 22 & 1.32 & 2.367 \\
Number of mentions of suicide attempts & 0 & 2 & .08 & .317 \\
\hline
\end{tabular}

TABLE 4. Definitions of Themes in Replies With Examples

\begin{tabular}{|c|c|c|}
\hline Theme & Definition & Examples \\
\hline Support & $\begin{array}{l}\text { Open offers of comfort and support, } \\
\text { such as their availability to listen or } \\
\text { sending their love and compliments }\end{array}$ & $\begin{array}{l}\text { Person A (15 yold non-binary person): "Still depressed } \\
\text { but getting better." } 7 \text { replies, } 10 \text { likes. } \\
\text { Responder: "Feel better plz *4 hearts*" } 3 \text { likes. } \\
\text { Person A: "I'll try." } 3 \text { likes. } \\
\text { Responder: "If you need someone to talk to you can } \\
\text { always DM me." } 3 \text { likes. } \\
\text { Person A: "I know." } \\
\text { Responder: "Love you, friend." } 2 \text { likes. } \\
\text { Person A: "*hearts." }\end{array}$ \\
\hline $\begin{array}{l}\text { Feeling the } \\
\text { same way }\end{array}$ & $\begin{array}{l}\text { Report having similar experiences } \\
\text { or feeling the same way }\end{array}$ & $\begin{array}{l}\text { Person B ( } 16 \text { y old trans male): "I'm just going to eat } \\
\text { and want to die furiously." } 2 \text { replies, } 1 \text { like. } \\
\text { Responder: "this is my entire life summed up in one } \\
\text { tweet." } 1 \text { like. }\end{array}$ \\
\hline Advice & $\begin{array}{l}\text { Offer specific advice to the account } \\
\text { holder }\end{array}$ & $\begin{array}{l}\text { Person C (17 y old trans female): "I hate that anxiety } \\
\text { is the only thing stopping me from overdosing right } \\
\text { now." } \\
\text { Responder: "You are scaring me. Please call (suicide } \\
\text { hotline number)." } 1 \text { like. } \\
\text { Person C: "no i don't deserve help." } \\
\text { Responder: "Yes you do. You deserve to live." } \\
\text { Person C: "no." } \\
\text { Responder: "You can also text (different phone number) } \\
\text { for help." } \\
\text { Person C: "no." }\end{array}$ \\
\hline
\end{tabular}

\section{DISCUSSION}

The majority of accounts searched in this data set received no replies to tweets found using the search terms; that is more than 700 tweets about psychological distress that were met with apparent silence. This begs the question of what purpose tweeting about their mental health issues serves the trans youth who create this content.
For some issues, such as self-harm, there were a plethora of tweets from a small number of accounts, some of which were self-described "vent accounts"; four accounts of this nature produced so many tweets on the same mental health issue that they were significant outliers in the data. Combined with the high percentage of tweets that had no replies, these findings suggest that expressing distress is an end in itself 
for many trans youth, as a form of catharsis or to build a narrative that makes sense of their difficult experiences.

Twitter is a convenient medium for short-form journaling; its rise as a platform correlates with the decline of long-form blogging sites (Kabadayi, 2014). Twitter has the benefit of allowing the expression of thoughts and emotions in the moment, rather than necessitating the composition of reflections afterward, although still allowing for this reflection. Personal journaling would constitute a counterintuitive use of social media, as it neglects the social features inherent in the format and raises the question of how many more of these accounts exist that are set to private.

Of those tweets that did gain replies, two of the themes most likely to receive replies were suicidal thoughts and self-harm, which were the two themes of the main issues of interest that were most strongly correlated to each other. It appears that there are unspoken social norms of giving each other space to "vent" but intervening by replying to offer support when the content of tweets suggests an escalation of risk.

The acknowledgment of experience appears to play a large role in what trans youth are seeking by reporting mental health issues online. It was rare that replies would question the account holder's perception of their situation; when they did, it was mostly to disagree when they reported something negative about themselves such as being "weak" or "stupid." Replies mostly acknowledged and validated how the account holder was struggling and announced their presence as support. The second most common form of reply expressed having similar experiences or feeling the same way, providing validation and bonding through common experience.

The rare occurrence of direct advice in replies were often negatively received or shut down, as seen in the example in Table 4. This suggests that in tweeting about their mental health issues, trans youth are not seeking information or potential solutions, and that this is generally understood by the community around them. This finding is concurrent with research that has looked at the way in which youth from the general population communicate about mental health issues online (Daine et al., 2013).

These results suggest a multipurpose role of Twitter for trans youth who are experiencing mental health issues: to quickly and easily express difficult experiences and emotions, to receive acknowledgment and support, and to know that they have peers who are going through or who have previously gone through the same experiences.

\section{It appears that there are unspoken social norms of giving each other space to "vent" but intervening by replying to offer support when the content of tweets suggests an escalation of risk.}

Some findings in this study are similar to findings among youth in the general population who discuss the same mental health issues on social media: common use of passive language when expressing suicidal thoughts, and mostly receiving validation and comfort rather than advice when communicating about mental health issues with their peers.

The primary difference between these findings and research into youth social media use is the apparent absence of encouragement of risky and selfinjurious behavior and/or dismissive responses to distress. The reverse of this was found, with suicidal thoughts and self-harm themes receiving the majority of replies offering support. This may mean that it is safer and potentially even beneficial for trans young people experiencing mental health issues to use a social media-based support network of peers, in comparison to youth in the general population.

It is tragically common to read about young people who have lost their lives to suicide after being encouraged to take this action by others on social media, and social media platforms have been under pressure to tackle this important issue (Campbell, 2020). The findings of this research show that there is another aspect of social media that does not make the news: the day-to-day work communities put into supporting and protecting each other with small kindnesses. A more nuanced understanding of how different groups use technology is vital so as not to deprive marginalized people, such as trans youth, of valuable resources.

\section{REFERENCES}

Caliandro, A., \& Gandini, A. (2016). Qualitative research in digital environments: A research toolkit. New York: Routledge.

Campbell, D. (2020). Social media firms "should hand over data amid suicide risk." The Guardian. Retrieved from 
https://www.theguardian.com/media/2020/jan/17/ academics-call-for-social-media-data-to-protect-young -people

Cho, A. (2018). Default publicness: Queer youth of color, social media, and being outed by the machine. New Media E Society, 20(9), 3183-3200. https://doi.org/10.1177/1461444817744784

Claes, L., Bouman, W. P., Witcomb, G., Thurston, M., Fernandez-Aranda, F., \& Arcelus, J. (2015). Nonsuicidal self-injury in trans people: Associations with psychological symptoms, victimization, interpersonal functioning, and perceived social support. Journal of Sexual Medicine, 12, 168-179. https://doi.org/ $10.1111 /$ jsm.12711

Colombo, G. B., Burnap, P., Hodorog, A., \& Scourfield, J. (2016). Analysing the connectivity and communication of suicidal users on twitter. Computer communications, 73, 291-300. https://doi.org/ 10.1016/j.comcom.2015.07.018

Craig, S. L., \& McInroy, L. (2014). You can form a part of yourself online: The influence of new media on identity development and coming out for LGBTQ youth. Journal of Gay E Lesbian Mental Health, 18, 95-109. https: / / doi.org/10.1080/19359705.2013.777007

Daine, K., Hawton, K., Singaravelu, V., Stewart, A., Simkin, S., \& Montgomery, P. (2013). The power of the web: A systematic review of studies of the influence of the internet on self-harm and suicide in young people. PLoS One, 8(10), e77555. https:/ / doi.org/10.1371/journal.pone.0077555

Eynon, R., Fry, J., \& Schroeder, R. (2008). The ethics of internet research. In N. G. Fielding, R. M. Lee, \& G. Blank (Eds.), The SAGE handbook of online research methods. pp. 23-41, London: Sage.

Fereday, J., \& Muir-Cochrane, E. (2006). Demonstrating rigor using thematic analysis: A hybrid approach of inductive and deductive coding and theme development. International Journal of Qualitative Methods, 5(1), 80-92. https:/ /doi.org/10.1177/160940690600500107

Hanckel, B., Vivienne, S., Byron, P., Robards, B., \& Churchill, B. (2019). "That's not necessarily for them": LGBTIQ+ young people, social media platform affordances and identity curation. Media, Culture and Society, 41, 1261-1278. https://doi.org/10.1177/0163443719846612 Retrieved from https://journals.sagepub.com/doi/full/10.1177/ 0163443719846612

Holt, V., Skagerberg, E., \& Dunsford, M. (2015). Young people with features of gender dysphoria: Demographics and associated difficulties. Clinical Child Psychology and Psychiatry, 21(1), 108-118. https:/ / doi.org/10.1177/1359104514558431

Kabadayi, O. (2014). Blogging is dead, long live blogging. The Guardian. Retrieved from https: / / www.theguardia n.com/media-network/media-network-blog/2014/jul /16/blogging-dead-bloggers-digital-content
Krueger, E. A., \& Young, S. D. (2015). Twitter: A novel tool for studying the health and social needs of transgender communities. JMIR Mental Health, 2(2), e16. https:/ / doi.org/10.2196/mental.4113

McDermott, E., Hughes, E., \& Rawlings, V. (2017). The social determinants of lesbian, gay, bisexual and transgender youth suicidality in England: a mixed methods study. Journal of Public Health, 40(3), 244-251. https://doi.org/10.1093/pubmed/fdx135

McDermott, E., Hughes, E., \& Rawlings, V. (2018). Norms and normalisation: Understanding lesbian, gay, bisexual, transgender and queer youth, suicidality and helpseeking. Culture, Health $\mathcal{E}$ Sexuality, 20(2), 156-172. https://doi.org/10.1080/13691058.2017.1335435

Meyer, I. H., \& Frost, D. M. (2013). Minority stress and the health of sexual minorities. In C. J. Patterson \& A. R. D'Augelli (Eds.), Handbook of psychology and sexual orientation (pp. 252-266). Oxford, UK: Oxford University Press.

Moreno, M. A., Ton, A., Selkie, E., \& Evans, Y. (2016). Secret society 123: Understanding the language of self-harm on Instagram. Journal of Adolescent Health, 58(1), 78-84. https:/ /doi.org/10.1016/j.jadohealth.2015.09.015

Murphy, S. C. (2017). A hands-on guide to conducting psychological research on Twitter. Social Psychological and Personality Science, 8(4), 396-412. https: / / doi.org/10.1177/1948550617697178

National Health Service. (2016). Treatment_Gender dysphoria. Retrieved from https://www.nhs.uk/conditions/gend er-dysphoria/treatment/

O’Dea, B., Achilles, M. R., Larsen, M. E., Batterham, P. J., Calear, A. L., \& Christensen, H. (2018). The rate of reply and nature of responses to suicide-related posts on Twitter. Internet interventions, 13, 105-107. https://doi.org/10.1016/j.invent.2018.07.004

Pardoe, J., \& Trainor, G. (2017). Transgender youths who self-harm: Perspectives from those seeking support. Mental Health Today. Retrieved from https:/ / www.men talhealthtoday.co.uk/transgender-youths-who-self-har m-perspectives-from-those-seeking-support

Rimes, K. A., Goodship, N., Ussher, G., Baker, D., \& West, E. (2017). Non-binary and binary transgender youth: Comparison of mental health, self-harm, suicidality, substance use and victimization experiences. International Journal of Transgenderism, 20, 1-11.

Rood, B. A., Reisner, S. L., Surace, F. I., Puckett, J. A., Maroney, M. R., \& Pantalone, D. W. (2016). Expecting rejection: Understanding the minority stress experiences of transgender and gender-nonconforming individuals. Transgender Health, 1(1), 151-164. https://doi.org/10.1089/trgh.2016.0012

Russell, K., Rasmussen, S., \& Hunter, S. (2018). Suicidal ideation in lesbian, gay, bisexual and transgender youth in Scotland: The role of defeat and entrapment. Ghent, Belgium: 17th European Symposium on Suicide \& Suicidal Behaviour. 
Spates, K., Ye, X., \& Johnson, A. (2018). "I just might kill myself": Suicide expressions on Twitter. Death Studies, 44(3), 189-194. https://doi.org/ 10.1080/07481187.2018.1531085

Disclosure. The author(s) have no relevant financial interest or affiliations with any commercial interests related to the subjects discussed within this article.

Funding. The author(s) received no specific grant or financial support for the research, authorship, and/or publication of this article.

Correspondence regarding this article should be directed to Drew Simms at drew_simms@outlook.com

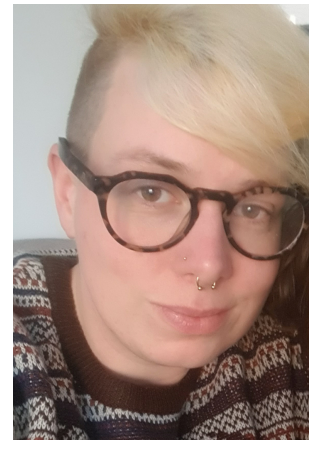

Drew Simms, MSc, BSc, BA, MSc, BSc, BA (hons) (they/them/their), an advocate for Victims of Transphobic Hate Crime in Galop, United Kingdom, and a psychiatric nurse at South West London and St George's NHS Trust, United Kingdom. They hold a BSc Nursing, Mental Health, from the University of Greenwich, a BA (Hons) in Communications and Psychology from Bath Spa University, and an MSc in Child and Adolescent Mental Health, King's College London, Institute of Psychiatry, Psychology and Neuroscience (loPPN). 